Jurnal Ilmu-Ilmu Peternakan 25 (2): 80 - 88

ISSN: 0852-3581

E-ISSN: 9772443D76DD3

CFakultas Peternakan UB, http://jiip.ub.ac.id/

\title{
Analisis kualitas pelayanan terhadap kepuasan konsumen dalam pembelian ayam goreng di "Ayam Goreng Roker" di Malang
}

\author{
Mohammad Fuaduzzaki Khoirurrohman, Budi Hartono dan Hari Dwi Utami \\ Fakultas Peternakan Universitas Brawijaya \\ Jl. Veteran Malang 65145 Jawa Timur
}

fuadzaki069@yahoo.com

\begin{abstract}
Study was conducted at "Ayam Goreng Roker" Bratan Lake Street C2 A11 and North Branch Sulfat Street 38 Malang. The purpose of this research was to determine customer satisfaction on quality services and factors that influence customer's satisfaction on purchasing fried chicken. One hundred respondents were selected by accidental sampling method. Data were collected from $12^{\text {th }}$ September to $12^{\text {th }}$ October 2014. Primary data were collected using questionnaire. Secondary data were obtained from Ayam Goreng Roker's archives and related sources. The study found that consumer satisfaction was represented by repeating buying, recommended to others of cheaper price, the appropriateness between packages and product, and fried chicken positive images. Consumer satisfaction increased as the availability of service quality including "skill of service and purchasing access", "worker's skill", "feasibility of location and worker's appearance", and also "parking facility". Whereas "feasibility of product, location and service" and "administration" were highly satisfying consumer in purchasing fried chicken.
\end{abstract}

Keywords : worker's skill, parking facility, access, administration

\section{PENDAHULUAN}

Kepuasan konsumen dapat terbentuk bila perusahaan mampu memberikan produk barang dan jasa sesuai dengan harapan konsumen. Salah satu cara untuk memberikan kepuasan kepada konsumen yaitu dengan meningkatkan kualitas pelayanan. Kualitas produk atau pelayanan yang diberikan perusahaan dan kepuasan konsumen berhubungan erat dengan keuntungan yang akan diperoleh perusahaan karena dengan kualitas produk yang memenuhi preferensi konsumen akan mengikat konsumen sehingga perusahaan tersebut tertanam dalam benak konsumen. Kualitas pelayanan memiliki nilai yang besar dalam membawa konsumen menuju ke tingkat kepuasan, sehingga kepuasan tersebut akan memberikan dampak positif bagi rumah makan ayam goreng Roker. Mandasari dan Tama (2011) menambahkan bahwa seorang konsumen mengalami berbagai tingkat kepuasan. Apabila produk tidak sesuai dengan harapannya, maka konsumen tersebut akan merasa tidak puas. Namun sebaliknya jika produk sesuai dengan harapannya, maka konsumen akan merasa puas sehingga suatu saat akan mengkonsumsi kembali produk 
tersebut. Konsumen yang puas adalah konsumen yang akan berbagi kepuasan dengan produsen. Bahkan, konsumen yang puas akan berbagi rasa dan pengalaman dengan konsumen lain. Hal ini tentunya menguntungkan bagi pihak rumah makan karena konsumen dapat menginformasikan kepada teman, keluarga ataupun kepada orang lain untuk mengkonsumsi produk atau jasa dari perusahaan tersebut. Kepuasan konsumen dapat menciptakan kesetiaan atau loyalitas konsumen kepada perusahaan. Restoran atau rumah makan baik lokal maupun restoran asing yang mengandalkan pelayanan (service) banyak sekali dibuka di Kota Malang. Bisnis penjualan ayam goreng semakin pesat sebagaimana dapat dilihat dari banyaknya rumah makan baru ataupun dengan membuka cabang di daerah lain. Kepuasan pelanggan merupakan respon pelanggan terhadap ketidaksesuaian antara tingkat kepentingan sebelumnya dan kinerja aktual yang dirasakannya setelah pemakaian (Rangkuti, 2002). Penelitian ini bertujuan untuk mengetahui kepuasan konsumen terhadap kualitas pelayanan yang diberikan dan mengetahui faktor-faktor yang berpengaruh terhadap kepuasan konsumen dalam pembelian ayam goreng.

\section{MATERI DAN METODE PENELITIAN}

\section{Lokasi dan waktu penelitian}

Penelitian dilakukan mulai 12 September 2014 sampai dengan 12 Oktober 2014 di "Ayam Goreng Roker" Jl. Danau Bratan C2 A11 Sawojajar dan Jl. Simpang Sulfat Utara 38 Kota Malang.

\section{Metode penentuan sampel}

Teknik pengambilan sampel untuk responden yang akan dijadikan sampel menggunakan metode accidental sampling. Accidental sampling adalah teknik penentuan sampel berdasarkan kebetulan, yaitu siapa saja yang kebetulan bertemu dengan peneliti dapat dipergunakan sebagai sampel bila dipandang orang yang kebetulan ditemui tersebut cocok sebagai sumber data. Pengambilan data dari 100 responden menggunakan kuesioner sebagai alat bantu penelitian. Metode penentuan sampel dengan kriteria bahwa pengunjung rumah makan "Ayam Goreng Roker" berusia dari 10-60 tahun.

\section{Metode pengumpulan data}

Data yang diperlukan adalah data primer dan data sekunder dengan tujuan untuk mengetahui dan menganalisis pengaruh kualitas layanan terhadap kepuasan konsumen bagi rumah makan. Data primer adalah data yang dikumpulkan oleh peneliti dari sumber pertama, sedangkan data sekunder adalah data yang bukan dari sumber pertama yang berasal dari catatan, arsip atau literatur. Data primer diperoleh dari hasil kuesioner yang diisi oleh responden dan data sekunder diperoleh dari data yang berasal dari catatan dan arsip rumah makan Ayam Goreng Roker.

\section{Analisis data}

\section{a. Uji validitas}

Pengukuran tingkat validitas item-item pertanyaan kuesioner terhadap tujuan pengukuran dilakukan dengan dengan cara melakukan korelasi antar skor item pertanyaan dengan skor variabel (Ghozali, 2005). Rumus yang digunakan untuk mengukur koefisien korelasi menurut Sanusi (2005) adalah sebagai berikut: 


$$
r=\frac{n \Sigma X Y-(\Sigma X)(\Sigma Y)}{\sqrt{\left\{n \Sigma X^{2}-(\Sigma X)^{2}\right\}\left\{n \Sigma Y^{2}-(\Sigma Y)^{2}\right\}}}
$$

Keterangan :

$$
\begin{aligned}
\mathrm{r} & =\text { koefisien korelasi } \\
\mathrm{n} & =\text { jumlah subyek/responden } \\
\mathrm{X} & =\text { nilai skor butir/nilai skor } \\
& \text { penentu } \\
\mathrm{Y} & =\text { nilai skor total } \\
\sum \mathrm{X}^{2} & =\text { jumlah kuadrat nilai } \mathrm{X} \\
\sum \mathrm{Y}^{2} & =\text { jumlah kuadrat nilai } \mathrm{Y}
\end{aligned}
$$

\section{b. Uji reliabilitas}

Suatu alat dikatakan reliable jika dapat mengukur suatu gejala yang berlainan dapat dipercaya dan dapat diandalkan. Reliabilitas suatu bisa diukur menggunakan cronbach alpha berdasarkan Bram (2005) yakni:

$$
r=\left\{\frac{K}{(K-1)}\right\}\left\{1-\frac{\Sigma \alpha_{b}^{2}}{\alpha_{t}^{2}}\right\}
$$

Keterangan :

$$
\begin{array}{ll}
\mathrm{r} & =\text { koefisien reliabilitas } \\
& \quad \text { instrument (cronbach alpha) } \\
\mathrm{k} & =\text { banyaknya butir pertanyaan } \\
\Sigma \alpha_{b}^{2} & =\text { total varians butir } \\
\alpha_{t}^{2} & =\text { total varians }
\end{array}
$$

\section{c. Uji analisis faktor}

Analisis faktor adalah analisis yang tepat untuk menganalisis data-data masukan yang berupa data matrik dan terdiri dari variabel-variabel dengan jumlah yang besar. Rumus analisa faktor yang dirumuskan oleh Malhotra (1996) adalah sebagai berikut :

$$
X_{i}=A_{i 1} F_{1}+A_{i 2} F_{2}+A_{i 3} F_{3}+\ldots+A_{i j} F_{j}+V_{i} U_{i}
$$

Keterangan:

$$
\begin{aligned}
\mathrm{X}_{\mathrm{i}} & =\text { variabel terstandar ter- } \mathrm{i} \\
\mathrm{A}_{\mathrm{ij}} & =\text { koefisien regresi dan variabel } \\
& \text { ke- } 1 \text { faktor umum } \mathrm{j} \\
\mathrm{F}_{\mathrm{j}} & =\text { faktor umum }
\end{aligned}
$$

$$
\begin{aligned}
\mathrm{V}_{\mathrm{i}}= & \text { koefisien regresi terstandar } \\
& \text { dari variabel i pada faktor } \\
& \text { khusus } \mathrm{i} \\
\mathrm{U}_{\mathrm{i}} \quad= & \text { faktor khusus bagi variabel } \mathrm{i}
\end{aligned}
$$

\section{d. Uji regresi berganda}

Sudjana (2003) menyebutkan bahwa regresi linier berganda digunakan untuk mengetahui dua variabel bebas atau lebih terhadap variabel terikat yang akan dihitung dengan persamaan sebagai berikut :

$$
\mathrm{Y}=\mathrm{a}+\mathrm{b}_{1} \mathrm{x}_{1}+\mathrm{b}_{2} \mathrm{X}_{2}+\ldots+\mathrm{b}_{5} \mathrm{X}_{5}+\mathrm{e}
$$

Keterangan :

$$
\begin{array}{ll}
\mathrm{Y} & =\begin{array}{l}
\text { Variabel terikat (kepuasan } \\
\text { konsumen) }
\end{array} \\
\mathrm{A} & =\text { Konstanta } \\
\mathrm{b}_{1}, . ., \mathrm{b}_{5}= & \text { Koefisien } \\
\mathrm{X}_{1} \quad=\text { Tangible (bukti nyata) } \\
\mathrm{X}_{2} \quad=\text { Reliability (keandalan) } \\
\mathrm{X}_{3} \quad=\text { Responsiveness (kesigapan) } \\
\mathrm{X}_{4} \quad=\text { Assurance (jaminan) } \\
\mathrm{X}_{5} \quad=\text { Empathy (empati) } \\
\mathrm{e} & =\text { standart error }
\end{array}
$$

\section{HASIL DAN PEMBAHASAN}

\section{Karakteristik responden}

Responden

penelitian didominasi oleh laki-laki sejumlah 53 orang sedangkan perempuan hanya sejumlah 47 orang. Mayoritas responden $(58 \%)$ berumur 20-30 tahun dengan tingkat pendidikan akhir tertinggi (52\%) adalah lulusan SMA dan berstatus sebagian besar $(50 \%)$ pelajar atau mahasiswa.

\section{Hasil analisis faktor}

Hasil analisis faktor menjelaskan bahwa dari 20 item variabel yang diajukan dapat diekstraksi menjadi 6 variabel baru yang dapat mewakili 20 variabel awal (Tabel 1). 
Tabel 1. Hasil analisis faktor kualitas pelayanan Ayam Goreng Roker

\begin{tabular}{|c|c|c|c|c|c|c|}
\hline \multirow{2}{*}{ Keterangan } & \multicolumn{6}{|c|}{ Loading faktor } \\
\hline & 1 & 2 & 3 & 4 & 5 & 6 \\
\hline \multicolumn{7}{|l|}{$\begin{array}{l}\text { Indeks } 1 \text { "kelayakan produk, tempat } \\
\text { dan pelayanan" }\end{array}$} \\
\hline $\mathrm{X}_{1.4}$ Kebersihan tempat & 0,526 & & & & & \\
\hline $\begin{array}{l}\mathrm{X}_{2.4} \text { Ketepatan janji terhadap } \\
\text { konsumen }\end{array}$ & 0,587 & & & & & \\
\hline $\mathrm{X}_{3.4}$ Kecepatan menangani keluhan & 0,692 & & & & & \\
\hline $\begin{array}{l}\mathrm{X}_{4.2} \text { Keamanan makanan dan } \\
\text { minuman }\end{array}$ & 0,852 & & & & & \\
\hline $\begin{array}{l}\mathrm{X}_{4.4} \text { Pengetahuan karyawan } \\
\text { terhadap produk }\end{array}$ & 0,592 & & & & & \\
\hline $\begin{array}{l}\mathrm{X}_{5.1} \text { Pemahaman terhadap } \\
\text { pelanggan }\end{array}$ & 0,530 & & & & & \\
\hline \multicolumn{7}{|l|}{$\begin{array}{l}\text { Indeks } 2 \text { "keterampilan pelayanan } \\
\text { dan akses pembelian" }\end{array}$} \\
\hline $\begin{array}{l}\mathrm{X}_{2.1} \text { Kemampuan dan keterampilan } \\
\text { melayani }\end{array}$ & & 0,563 & & & & \\
\hline $\mathrm{X}_{2.3}$ Keakuratan administrasi & & 0,742 & & & & \\
\hline $\begin{array}{l}\mathrm{X}_{3.1} \text { Kesediaan membantu } \\
\text { konsumen }\end{array}$ & & 0,774 & & & & \\
\hline $\mathrm{X}_{5.3}$ Kemudahan akses pembelian & & 0,550 & & & & \\
\hline \multicolumn{7}{|l|}{ Indeks 3 "ketepatan administrasi" } \\
\hline $\mathrm{X}_{3.3}$ Kecepatan transaksi & & & 0,534 & & & \\
\hline $\begin{array}{l}\mathrm{X}_{4.3} \text { Perhatian pegawai terhadap } \\
\text { pelanggan }\end{array}$ & & & 0,748 & & & \\
\hline $\begin{array}{l}\mathrm{X}_{5.4} \text { Pemahaman menu yang } \\
\text { diinginkan konsumen }\end{array}$ & & & 0,694 & & & \\
\hline \multicolumn{7}{|l|}{ Indeks 4 "keterampilan pegawai" } \\
\hline $\begin{array}{l}\mathrm{X}_{2.2} \text { Kecepatan dan ketepatan } \\
\text { menyajikan }\end{array}$ & & & & 0,522 & & \\
\hline $\begin{array}{l}\mathrm{X}_{3.2} \text { Kesediaan menerima saran dan } \\
\text { keluhan }\end{array}$ & & & & 0,650 & & \\
\hline $\mathrm{X}_{4.1}$ Kesopanan pegawai & & & & 0,588 & & \\
\hline $\begin{array}{l}\mathrm{X}_{5.2} \text { Kemampuan berbahasa yang } \\
\text { baik }\end{array}$ & & & & 0,622 & & \\
\hline $\begin{array}{l}\text { Indeks } 5 \text { "kelayakan lokasi dan } \\
\text { penampilan pegawai" }\end{array}$ & & & & & 0,765 & \\
\hline $\begin{array}{l}\mathrm{X}_{1.1} \text { Kenyamanan tempat } \\
\mathrm{X}_{1.2} \text { Penampilan karyawan }\end{array}$ & & & & & 0,502 & \\
\hline Indeks 6 "kelayakan fasilitas parkir" & & & & & & \\
\hline $\mathrm{X}_{1.3}$ Kerapian dan keamanan parkir & & & & & & 0,830 \\
\hline Varians \% & 29,89 & 8,66 & 7,89 & 6,70 & 5,11 & 5,03 \\
\hline
\end{tabular}


Faktor baru berjumlah 6 faktor yang memiliki nilai eigen value diatas 1 atau $\geq 1$. Seleksi faktor dilakukan dengan cara menyeleksi nilai faktor loading yang terbentuk dan dipilih nilai faktor loading terbesar atau minimum bernilai 0,4 agar dapat mewakili masing-masing faktor sehingga faktor inilah yang akan digunakan pada analisis selanjutnya.

Tahap berikutnya adalah pemberian nama pada faktor baru yang telah terbentuk. Suliyanto (2005) menyatakan bahwa untuk menamai faktor yang telah terbentuk dalam analisis faktor dapat dilakukan dengan cara memberikan nama faktor yang dapat mewakili nama-nama variabel. Hal ini berarti bahwa 63,28\% keragaman 6 faktor baru mampu dibentuk melalui 20 variabel yang telah diajukan serta sisanya $(36,72 \%)$ dijelaskan oleh variabel lain yang tidak diteliti pada penelitian ini.

Faktor kelayakan produk, tempat dan pelayanan memiliki variabel yang berpengaruh kuat pada Ayam Goreng Roker yaitu keamanan makanan dan minuman yang memiliki nilai faktor loading sebesar 0,852. Keamanan makanan dan minuman harus terjamin, sehingga konsumen tidak merasa cemas untuk mengkonsumsi produk yang disajikan. Kebersihan tempat meliputi meja yang telah digunakan langsung dibersihkan oleh pegawai sebelum konsumen yang baru masuk. Kebersihan tempat juga mencakup kondisi lantai, piring dan gelas yang digunakan, peralatan dapur serta fasilitas yang disediakan.

Variabel yang paling berpengaruh pada faktor keterampilan pelayanan dan akses pembelian adalah kesediaan membantu konsumen yang memiliki loading faktor terbesar yaitu 0,774. Kesediaan pegawai dalam membantu konsumen untuk menjelaskan menu-menu yang ditawarkan, menghindari kesalahan dalam pemesanan yang akan berdampak mengecewakan konsumen. Keakuratan administrasi meliputi ketepatan dalam penghitungan pembayaran, pemberian struk pembelian dan pemberian nomor meja. Kemampuan dan keterampilan melayani meliputi bagaimana pegawai memberikan sapaan ketika konsumen datang hingga konsumen meninggalkan tempat. Pemberian menu ketika konsumen telah berada di meja, tata cara membawa dan memberikan makanan dan minuman berpengaruh pada konsumen. Kemudahan akses pembelian menuju Ayam Goreng Roker harus baik, artinya konsumen dapat dengan mudah mencapai lokasi menggunakan berbagai macam alat transportasi dan jalan yang dilalui tidak mengalami masalah.

$$
\text { Variabel yang paling }
$$

berpengaruh pada faktor ketepatan administrasi adalah perhatian pegawai terhadap pelanggan yang memiliki nilai loading faktor sebesar 0,748 . Perhatian terhadap pelanggan berupa penjelasan kepada konsumen jika ada menu atau hal lain yang belum dipahami oleh konsumen. Kecepatan transaksi dalam pembayaran dengan menghitung pembayaran secara tepat.

$$
\text { Variabel yang paling }
$$

berpengaruh pada faktor keterampilan pegawai adalah kesediaan menerima saran dan keluhan yang memiliki faktor loading sebesar 0,650. Kesediaan pihak Ayam Goreng Roker ini akan memperbaiki pelayanan maupun fasilitas sehingga konsumen ingin datang kembali. Kecepatan dan ketepatan penyajian akan mempengaruhi rasa senang konsumen karena tidak lama dalam menunggu produk yang telah dipesan. Kesopanan pegawai meliputi sikap yang ditunjukkan ketika menerima konsumen 
saat penyajian hingga konsumen meninggalkan tempat.

$$
\text { Variabel yang paling }
$$

berpengaruh pada faktor kelayakan lokasi dan penampilan pegawai adalah kenyamanan tempat yang memiliki loading faktor sebesar 0,765. Kenyamanan tempat meliputi suasana rumah makan yang dilengkapi dengan musik, hiasan, fasilitas ibadah dan kamar mandi. Penampilan karyawan meliputi baju seragam yang dikenakan pegawai memiliki ciri khas Ayam Goreng Roker.

Variabel yang berpengaruh terhadap persepsi konsumen mengenai fasilitas parkir yaitu kerapian dan keamanan parkir yang memiliki faktor loading sebesar 0,830. Kerapian dan keamanan parkir antara lain tersedianya lahan dan penjaga parkir untuk menjaga alat transportasi pribadi milik konsumen. Fasilitas ini disediakan agar konsumen merasa aman dan tenang terhadap kendaraan yang dibawa.

\section{Hasil analisis regresi berganda kualitas pelayanan}

Variabel terikat atau dependent variable dalam penelitian ini adalah kepuasan konsumen sedangkan variabel bebas/independen adalah variabel kualitas pelayanan yang sebelumnya telah dilakukan analisis faktor sehingga terbentuk menjadi enam faktor, kemudian ditambah dengan variabel karakteristik konsumen dan faktor lingkungan. Nilai $\mathrm{R}$ square sebesar 0,543 artinya variabel independen yang meliputi kualitas pelayanan, karakteristik konsumen dan faktor lingkungan mampu menjelaskan kepuasan konsumen pada rumah makan Ayam Goreng Roker sebesar 54,3\%, sedangkan sisanya dijelaskan oleh faktor lain. Konstanta pada persamaan regresi berganda diatas sebesar 15,956 yang artinya jika semua variabel bebas (kualitas pelayanan) bernilai 0 maka kepuasan konsumen memiliki nilai sebesar 15,956.

Pengujian model regresi secara parsial digunakan untuk mengetahui apakah masing-masing variabel independen pembentuk model regresi secara individu memiliki pengaruh yang signifikan terhadap kepuasan konsumen atau tidak. Uji $\mathrm{t}$ digunakan untuk menguji hubungan tersebut, yakni membandingkan nilai thitung dengan $t_{\text {tabel }}$. Variabel independen pembentuk model regresi dikatakan berpengaruh signifikan jika $t_{\text {hitung }}>t_{\text {tabel }}$ atau signifikan $<\alpha=0,05$. Hasil pengujian analisis regresi berganda menghasilkan model regresi sebagai berikut :

$$
\mathrm{Y}=15,956 \mathrm{~A}+0,387 \mathrm{~F}_{1}+0,251 \mathrm{~F}_{2}+0,380 \mathrm{~F}_{3}+0,244 \mathrm{~F}_{4}+0,253 \mathrm{~F}_{5}+0,133 \mathrm{~F}_{6}
$$

$$
\begin{array}{ll}
\text { Keterangan : } \\
\mathrm{Y} \quad \text { = Kepuasan konsumen } \\
\mathrm{A} & =\text { Konstanta } \\
\mathrm{F}_{1} & =\text { Kelayakan produk, tempat dan pelayanan } \\
\mathrm{F}_{2} & =\text { Keterampilan pelayanan dan akses pembelian } \\
\mathrm{F}_{3} & =\text { Ketepatan administrasi } \\
\mathrm{F}_{4} & =\text { Keterampilan pegawai } \\
\mathrm{F}_{5} & =\text { Kelayakan lokasi dan penampilan pegawai } \\
\mathrm{F}_{6} & =\text { Kelayakan fasilitas parkir }
\end{array}
$$


Kelayakan produk, tempat dan pelayanan

Nilai "koefisien kelayakan produk, tempat dan pelayanan" sebesar 0,387 dan bertanda positif. Hal ini dapat dikatakan "kelayakan produk, tempat dan pelayanan" searah dengan kepuasan konsumen dan nilai koefisien yang cukup tinggi menunjukkan adanya pengaruh faktor yang terdiri dari kebersihan tempat, ketepatan janji terhadap konsumen, kecepatan menangani keluhan, keamanan makanan dan minuman, pengetahuan karyawan terhadap produk dan pemahaman terhadap pelanggan secara bersamasama akan mempengaruhi kepuasan konsumen Ayam Goreng Roker. Fen and Lian (2006) menyatakan bahwa fasilitas rumah makan yang diperbaiki dengan menjamin kebersihan dan pemberian suasana yang baik berupa penambahan musik dan pencahayaan dapat mempengaruhi kepuasan konsumen.

\section{Keterampilan pelayanan dan akses pembelian}

Nilai koefisien "keterampilan pelayanan dan akses pembelian" sebesar 0,251 dan bertanda positif. Hal ini dapat dikatakan "keterampilan pelayanan dan akses pembelian" searah dengan kepuasan konsumen dan menunjukkan adanya pengaruh faktor-faktor kemampuan dan keterampilan dalam melayani, keakuratan administrasi, kesediaan membantu konsumen dan kemudahan akses pembelian secara bersama-sama akan mempengaruhi kepuasan konsumen Ayam Goreng Roker.

\footnotetext{
"Ketepatan administrasi"

Nilai koefisien "ketepatan administrasi" adalah 0,380 dan bertanda positif. Hal ini dapat dikatakan "ketepatan administrasi" searah dengan
}

kepuasan konsumen dan nilai koefisien yang cukup tinggi menunjukkan adanya pengaruh faktor yang terdiri dari kecepatan transaksi, perhatian pegawai terhadap pelanggan dan pemahaman menu yang diinginkan konsumen secara bersama-sama akan mempengaruhi kepuasan konsumen Ayam Goreng Roker.

\section{"Keterampilan pegawai"}

Nilai koefisien "keterampilan pegawai" adalah 0,244 dan bertanda positif. Hal ini dapat dikatakan "keterampilan pegawai" searah dengan kepuasan konsumen. Saran dan keluhan dari konsumen memiliki hal penting yang dapat memberikan perbaikan kepada rumah makan Ayam Goreng Roker sehingga dapat terus bertahan bahkan semakin berkembang. Kesopansantunan karyawan yang mampu ditunjukkan kepada konsumen akan berdampak pada kenyamanan konsumen Ayam Goreng Roker. Hal ini didukung oleh pendapat Zeithaml and Bitner (2004) yang menyatakan bahwa pengetahuan, kesopansantunan dan kemampuan para pegawai perusahaan dapat menumbuhkan rasa percaya para pelanggan kepada pelayanan perusahaan.

\section{"Kelayakan lokasi dan penampilan pegawai"}

Nilai koefisien "kelayakan lokasi dan penampilan pegawai" adalah 0,253 dan bertanda positif. Hal ini dapat dikatakan "kelayakan lokasi dan penampilan pegawai" searah dengan kepuasan konsumen. Kenyamanan tempat yang disediakan Ayam Goreng Roker meliputi kebersihan maupun tata ruangan. Lingkungan Ayam Goreng Roker yang bersih serta jauh dari sampah, peralatan makan dan fasilitas lain yang disediakan bersih mampu membuat konsumen merasa nyaman 
untuk menikmati makanan dan minuman di Ayam Goreng Roker. Hal ini didukung oleh Agustina (2011) yang berpendapat bahwa faktor situasi (waktu yang tersedia untuk belanja, jumlah produk yang tersedia, lokasi toko, ketersediaan informasi, kondisi psikologis konsumen, resiko sosial dari situasi dan tujuan belanja) akan mempermudah konsumen mendapatkan apa yang diinginkan.

\section{"Kelayakan fasilitas parkir"}

Nilai koefisien "kelayakan fasilitas parkir" yaitu 0,133 dan bertanda positif. Hal ini dapat dikatakan "kelayakan fasilitas parkir" searah dengan kepuasan konsumen. Fasilitas parkir yang disediakan Ayam Goreng Roker memiliki lahan yang cukup luas dan disediakan penjaga parkir untuk menjaga alat transportasi konsumen. Konsumen yang datang merasa aman karena telah tersedia penjaga untuk menjaga kendaraan para konsumen. Tersedianya sarana parkir yang memadai dan aman merupakan faktor yang mempengaruhi konsumen dalam pembelian suatu produk, karena hal ini dapat memberikan keamanan dan kenyamanan terutama dari gangguan pengamen, pedagang asongan dan pengemis. Tabel 2 merupakan penjabaran dari hasil analisis regresi kualitas pelayanan.

Tabel 2. Hasil analisis regresi berganda kualitas pelayanan

\begin{tabular}{lc}
\hline Keterangan & Koefisien regresi \\
\hline Konstanta & 15,956 \\
F1 ("kelayakan produk, tempat dan pelayanan”) & $0,387^{* * *}$ \\
F2 ("keterampilan pelayanan dan akses pembelian”) & $0,251^{* *}$ \\
F3 ("ketepatan administrasi”) & $0,380^{* * *}$ \\
F4 ("keterampilan pegawai”) & $0,244^{* *}$ \\
F5 ("kelayakan lokasi dan penampilan pegawai") & $0,253^{* *}$ \\
F6 ("kelayakan fasilitas parkir") & $0,133^{*}$ \\
X6 (usia) & 0,001 \\
X7 (jenis kelamin) & 0,013 \\
X8 (pendidikan terakhir) & $-0,008$ \\
X9 (pekerjaan) & $-0,156$ \\
X10 (penghasilan) & $-0,116$ \\
X11 (budaya) & $-0,009$ \\
X12 (situasi) & 0,055 \\
X13 (pengolahan informasi) & 0,034 \\
\hline R Square (R²) & $54,3 \%$ \\
Radjusted & $46,8 \%$ \\
F-Hitung & 7,218 \\
N & 100 \\
\hline Keterangan:
\end{tabular}

Keterangan:

$$
\begin{array}{ll}
\text { “" } & : \text { hasil analisis faktor } \\
* * * & : \text { sangat signifikan }(\rho<0,001) \\
* * & : \text { signifikan }(\rho<0,05) \\
* & : \text { signifikan }(\rho<0,1)
\end{array}
$$




\section{KESIMPULAN}

Penelitian ini menyimpulkan bahwa kepuasan konsumen diwujudkan setelah mengkonsumsi produk dan merekomendasikan kepada orang lain, harga yang cukup murah, kesesuaian harga dengan ukuran kemasan produk dan tidak ada komplain terhadap pelayanan serta berbicara positif kepada orang lain. Selain itu, kepuasan konsumen dapat ditingkatkan dengan kualitas pelayanan berupa "keterampilan pelayanan dan akses pembelian" "keterampilan pegawai", "kelayakan lokasi dan penampilan pegawai" dan "kelayakan fasilitas parkir" memiliki pengaruh positif terhadap kepuasan konsumen, sedangkan"kelayakan produk, tempat dan pelayanan" dan "ketepatan administrasi" memiliki pengaruh sangat dominan terhadap kepuasan konsumen.

\section{DAFTAR PUSTAKA}

Agustina, S. 2011. Manajemen pemasaran. UB Press. Malang.

Bram, Y. F. 2005. Analisis efektifitas iklan sebagai salah satu strategi pemasaran perusahaan percetakan dan penerbitan PT Rambang dengan menggunakan metode EPIC model. Jurnal Manajemen Dan Bisnis Sriwijaya, Vol. 3, No.6 : 1-23.

Fen, Y. S and Lian, K. M. 2006. Service quality and customer satisfaction: antecedents of customer's repatronage intentions. Sunway Academic Journal 4.
Ghozali, I. 2005. Aplikasi analisis multivariat dengan program SPSS. Badan Penerbit Universitas Diponegoro. Semarang.

Malhotra. 1996. Marketing research and applied orientation. Prentice Hall. New York.

Mandasari, V dan Tama, B. A. 2011. Analisis kepuasan konsumen terhadap restoran cepat saji melalui pendekatan data mining: studi kasus XYZ. Jurnal Generic Vol. 6 No. 1.

Rangkuti, F. 2002. Measuring customer satisfaction teknik mengukur dan strategi meningkatkan kepuasan pelanggan dan analisis kasus PLN-JP. PT. Gramedia Pustaka Utama. Jakarta

Sanusi, R. S. 2005. Beberapa uji validitas dan reliabilitas pada instrumen penelitian. Artikel Seminar hasil penelitian staf pengajar Departemen Biostatistika dan Kependudukan Universitas Sumatera Utara Medan. Hal 113116.

Sudjana. 2003. Teknik analisis regresi dan korelasi bagi para peneliti. Tarsito. Bandung.

Suliyanto. 2005. Analisis data dalam aplikasi pemasaran. Ghalia. Bogor.

Zeithaml, V. A and M. J. Bitner. 2004. Service marketing : integrating customer focus across the film. Journal 3rd Ed, Mc Graw Hill, New York. 